\title{
SELEKSI KARYAWAN PADA POSISI ASSISTANT SUPERINTENDENT
}

\author{
Rislisa, Mukhaira El Akmal \\ Fakultas Psikologi, Universitas Prima Indonesia \\ icha_candyd@yahoo.com
}

\begin{abstract}
All organization or company needs human resources in carrying out every function of activity. The need of human resources is very important because in gaining superior human resources cannot be obtained easily; it takes a way to get the right labor to fill a certain position by selection. It is hoped that by doing this process, we will get reliable human resources, which are needed to meet the needs of the organization in the present and future. Selection activities are conducted in the framework of community service activities. The target of community service is to accompany the company so that prospective new employees who follow the selection process at the psychological test stage can complete all the test stages. The selection of superintendent assistant positions is done by the Psychology Test Method (to reveal aspects of intelligence, work attitude, and personality), Leaderless Group Discussion (LGD), and Psychological Interview. This test was followed by 203 participants. As a result of the whole process, 136 participants were graduated.
\end{abstract}

Key words: selection, employees, assistant superintendent.

\begin{abstract}
Abstrak
Setiap organisasi atau perusahaan membutuhkan Sumber Daya Manusia dalam melaksanakan setiap fungsi kegiatan yang ada didalamnya. Kebutuhan akan Sumber Daya Manusia sangatlah penting karena menentukan maju mundurnya perusahaan. Sumber Daya Manusia yang unggul tidak dapat diperoleh dengan begitu saja, diperlukan suatu cara agar diperoleh tenaga kerja yang tepat untuk mengisi posisi tertentu di perusahaan, yaitu dengan seleksi. Diharapkan dengan dilakukannya proses ini, maka akan diperoleh sumber daya manusia yang handal, yang diperlukan untuk memenuhi kebutuhan organisasi di masa sekarang dan yang akan datang. Kegiatan seleksi ini dilakukan dalam rangka kegiatan Pengabdian Masyarakat. Target pengabdian masyarakat ini adalah mendampingi perusahaan agar calon karyawan baru yang mengikuti kegiatan seleksi pada tahap tes psikologi dapat menyelesaikan seluruh tahapan tes yang ada. Seleksi posisi assistant superintendent ini, dilakukan dengan metode Tes Psikologi (untuk mengungkap aspek kecerdasan, sikap kerja, dan kepribadian), Leaderless Grup Discussion (LGD), dan Wawancara Psikologis. Tes ini diikuti oleh 203 peserta. Hasil dari keseluruhan proses ini, diperoleh 136 orang peserta yang lulus.
\end{abstract}

Kata kunci: seleksi, karyawan, assistant superintendent. 


\section{PENDAHULUAN}

Setiap organisasi atau perusahaan dalam menjalankan semua aktivitasnya memiliki tujuan. Dalam rangka pencapaian tujuan tersebut organisasi atau perusahaan perlu memperhatikan keterkaitan antara faktor-faktor produksi yang terdiri dari sumber daya alam, sumber daya manusia, modal, bahan baku, mesin, dan teknologi. Organisasi dituntut untuk dapat mengelola organisasi dengan sebaik-baiknya terutama pada bidang sumber daya manusia agar mampu bekerja lebih baik dan efisien (Widiyantoro, 2012). Keberhasilan suatu organisasi secara umum ditentukan oleh orang-orang yang terlibat dalam struktur organisasi tersebut. Karyawan adalah asset utama perusahaan yang menjadi perencana, pelaku dari penentu tercapainya suatu tujuan dari suatu organisasi (Rafii \& Andri, 2015).

Salah satu bentuk inovasi yang ditawarkan para ahli SDM dalam pengelolaan SDM yang dimiliki sebagai asset perusahaan berhubungan dengan perolehan tenaga kerja yang tepat sesuai dengan kebutuhan organisasi. Ketepatan dalam merekrut dan menyeleksi tenaga kerja suatu organisasi sangat menentukan keefektifan organisasi, baik ditinjau dari sisi performa individu dan organisasi, profitabilitas yang dihasilkan dan tercapainya tujuan jangka panjang organisasi (Sujanto, 2009). Maka dalam hal ini dibutuhkan karyawan yang sesuai untuk menduduki posisi jabatan yang ada, oleh karena itu organisasi perlu melakukan proses seleksi karyawan. Menurut Mondy (2008), seleksi adalah proses memilih sekelompok pelamar individu yang paling sesuai untuk posisi tertentu dalam organisasi. Proses seleksi karyawan yang terintegrasi menjadi salah satu cara yang ampuh untuk mendapatkan karyawan yang unggul dan berkinerja optimal. Hal tersebut sependapat dengan yang dikatakan oleh Mondy (2008) bahwa proses seleksi menjadi gerbang awal bagi setiap perusahaan untuk untuk mendapatkan para karyawan yang handal dan berkualitas.

Menurut Ardana, dkk (2012) bahwa untuk mendapatkan SDM yang berdaya guna dan berhasil maka diperlukan beberapa kriteria sebagai dasar dalam mengadakan seleksi, yaitu:

1. Seleksi berpedoman pada analisa jabatan. Dalam deskripsi jabatan dan spesifikasi jabatan yang merupakan hasil dari analisa jabatan tercantum rincian tugas dan tanggung jawab serta kriteria yang harus dipenuhi oleh para pelamar. Oleh karena itu, deskripsi dan spesifikasi jabatan harus dijadikan pedoman dalam seleksi SDM agar selektif pelaksanaannya dan dapat dijamin keberhasilannya.

2. Seleksi harus efektif dan efisien. Proses seleksi harus dilaksanakan tepat sesuai dengan alokasi dana, waktu dan rencana yang telah ditetapkan. Efisien adalah peleksanaan seleksi memerlukan dana yang sesuai dengan anggaran yang tersedia tetapi dapat memilih SDM yang tepat.

3. Seleksi berpedoman pada perencanaan SDM. Dalam perencanaan kebutuhan jumlah SDM tertuang berapa jumlah SDM yang diperlukan untuk mengisi lowongan pekerjaan yang tersedia. Seleksi mengacu pada banyaknya SDM yang dibutuhkan tidak terpenuhi oleh calon tenaga kerja atau pelamar maka seleksi ulang bisa dilaksanakan untuk periode berikutnya sehingga mendapatkan SDM yang tepat. 
Rislisa, dkk. Seleksi Karyawan Pada Posisi Assistant Superintendent...

4. Seleksi harus memperhatikan peraturan dan ketentuan yang berlaku dalam pelaksanaan seleksi harus memperhatikan peraturan.

5. Seleksi harus dilaksanakan objektif dan jujur. Objektivitas dan kejujuran seleksi menjadi tumpuan harapan bagi para pelamar karena dengan cara demikian, kepuasan dan keberhasilan dalam seleksi akan dirasakan dengan penuh kebanggaan.

Melihat kebutuhan dalam pemenuhan karyawan untuk menempati posisi yang sesuai dengan kualifikasi yang ada, mitra kami membutuhkan bantuan untuk melakukan seleksi karyawan pada posisi assistant superintendent. Pada kesempatan ini, kami mengambil peran untuk berkontribusi dalam mendampingi perusahaan tersebut untuk melakukan seleksi karyawan sebagai kegiatan pengabdian yang dapat kami lakukan. Dalam kegiatan ini kami membantu pada tahap tes psikologi, tahap Leaderless Grup Discussion (LGD), dan wawancara. Pengabdian masyarakat ini bertujuan agar mendapatkan karyawan yang sesuai dengan kualifikasi yang dibutuhkan. Diharapkan para peserta yang ikut dalam program ini juga dapat terseleksi dengan cepat, tepat, efisien, efektif dan objektif.

\section{METODE PELAKSANAAN}

Kegiatan pengabdian masyarakat dalam program seleksi karyawan ini dibagi dalam beberapa tahapan, yaitu: (1) seleksi berkas; (2) tes TPA; (3) tes psikologi, Leaderless Grup Discussion (LGD), dan wawancara (4) Wawancara User; (5) Tes Kesehatan; dan (6) Pemagangan. Adapun pengabdian ini akan difokuskan pada penjelasan mengenai tahapan tes psikologi, Leaderless Grup Discussion (LGD), dan wawancara. Pada tahap tes psikologi ini, seperti yang terlihat pada gambar 1, terlebih dahulu seluruh peserta mengisi lembar lingkungan kehidupan (LK), self inventory, dan dilanjutkan dengan pemberian tes psikologi. Tes ini dilakukan untuk melihat dinamika psikologi dari calon karyawan tersebut yang dapat dilihat dari aspek intelektual, aspek sikap kerja, dan aspek kepribadian.

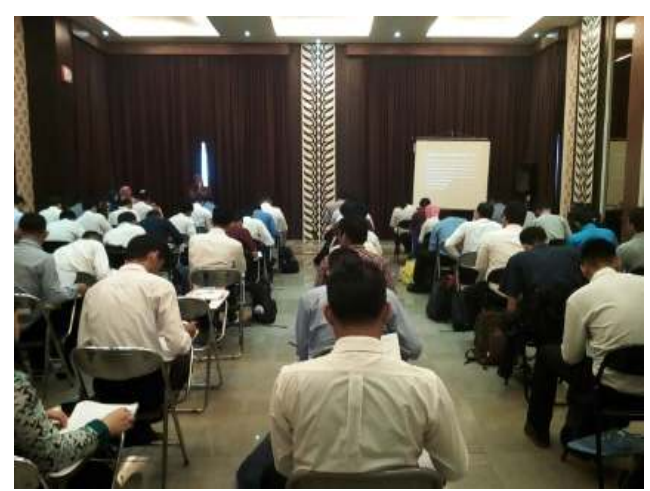

Gambar 1: Tahap Tes Psikologi

Setelah tahap tes psikologi selesai dilanjutkan pada tahap Leaderless Grup Discussion (LGD) seperti yang terlihat pada gambar 2 . Pada tahap ini peserta dibagi dalam beberapa kelompok kemudian tugas mereka dalam kelompok tersebut adalah mendiskusikan solusi dari suatu permasalahan. Pada sesi ini, dapat dilihat bagaimana kemampuan komunikasi, kepemimpinan, kerjasama, dan kemampuan peserta dalam membuat keputusan di dalam tim kerjanya. 


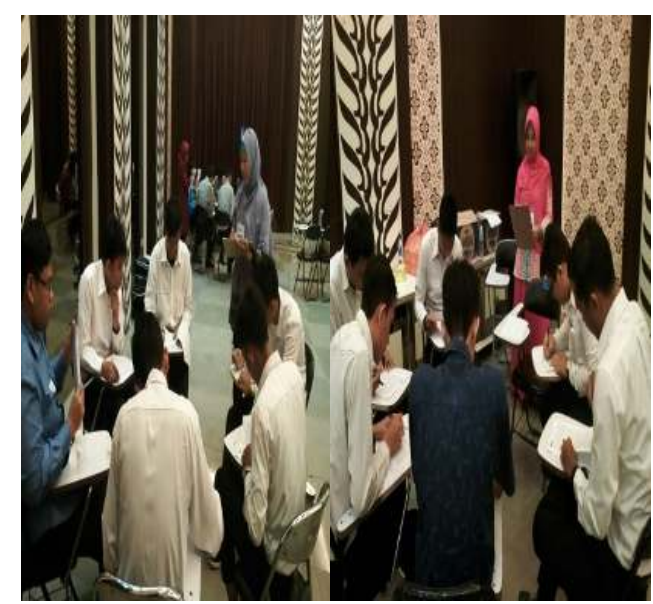

Gambar 2: Tahap Leaderless Grup Discussion (LGD)

Tahapan selanjutnya adalah wawancara seperti yang terlihat pada gambar 3. Peserta diminta untuk menjawab dan menceritakan pengalaman mereka terkait dengan halhal yang ditanyakan oleh asesor. Pada tahapan ini, asesor juga mengkonfirmasi hal-hal yang meragukan saat proses psikotes dan LGD berlangsung.

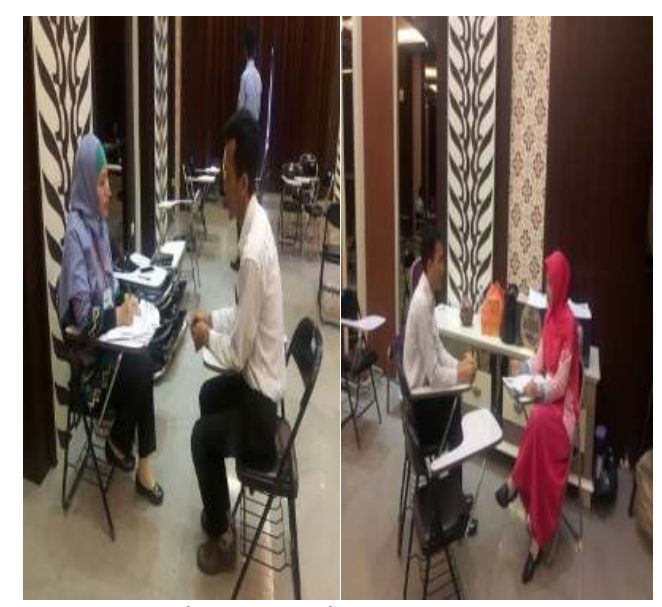

Gambar 3: Tahap Wawancara

\section{HASIL DAN PEMBAHASAN}

Hasil kegiatan pengabdian masyarakat dalam program seleksi karyawan ini secara garis besar mencakup beberapa komponen, yaitu:

1. Pencapaian tujuan pengabdian; dan
2. Pencapaian target peserta yang lulus seleksi.

Target tujuan pengabdian ini adalah secara umum setiap calon karyawan baru yang mengikuti kegiatan seleksi pada tahap tes psikologi dapat menyelesaikan seluruh tahap tes yang ada, yaitu yang dimulai dari tahap menjawab setiap tes psikologi, LGD, dan wawancara dilakukan sesuai dengan prosedur yang ada serta setiap calon karyawan baru dapat menyelesaikan setiap tahapnya.

Proses seleksi yang dilakukan dalam pengabdian ini termasuk sebagai fungsi-fungsi MSDM yang mempunyai peranan strategis dalam mempersiapkan dan menyediakan sumber daya manusia yang sesuai dengan kebutuhan pekerjaan, sebagaimana ditetapkan dalam analisis pekerjaan, khususnya deskripsi dan spesifikasi pekerjaan. Sebagai bagian dari penerapan kebijakan perusahaan, maka penerapan prinsip seleksi menjadi faktor stimulus (pendorong) yang dapat mempengaruhi perubahan di dalam perusahaan.

Dalam hal ini seleksi tenaga kerja dimaksudkan untuk memilih tenaga kerja yang memenuhi persyaratan, baik kuantitas dan kualitasnya. Oleh karenanya merupakan suatu keharusan untuk mengadakan pemilihan dari tenaga-tenaga kerja yang bersedia bekerja dalam organisasi agar mendapatkan orang-orang yang mempunyai kualifikasi sesuai dengan kebutuhan. Organisasi harus menyadari bahwa tidak ada artinya jika menempatkan tenaga kerja yang tidak cakap atau tidak mempunyai kualifikasi yang sesuai dengan suatu jabatan yang akan diberikan.

Penerapan sistem atau kebijaksanaan organisasi baik dalam pelaksanaan perekrutan, seleksi dan khususnya dalam penempatan tenaga 
Rislisa, dkk. Seleksi Karyawan Pada Posisi Assistant Superintendent...

kerja yang tepat pada posisi yang tepat pada posisi yang tepat dan dirancang dapat mencapai daya guna dan hasil guna yang sebesar-besarnya sesuai dengan rencana yang telah ditetapkan sebelumnya. Dengan penempatan tenaga kerja yang tepat diharapkan dapat menumbuhkan motivasi kerja karyawan dalam meningkatkan produktivitasnya.

Nurhuda, Hamid, dan Riza (2014), mengatakan bahwa sukses atau tidaknya suatu organisasi tergantung dari karyawannya yang mampu menjalankan kegiatan operasional organisasi sesuai dengan tujuan organisasi tersebut. Sehingga tidak salah, jika perusahaan menginginkan karyawan yang kompeten, yang mampu melaksanakan tugas yang diberikan perusahaan dengan penuh tanggung jawab. Kondisi seperti ini diperoleh jika perusahaan memperoleh karyawan yang berkompeten, yang melalui proses seleksi yang sesuai dengan kualifikasi pekerjaan yang diperlukan.

Senada dengan hal tersebut, Ardana, dkk (2012) menyatakan bahwa seleksi SDM sangat penting karena tiga alasan, yaitu:

1. Kinerja perusahaan akan selamanya bergantung pada kinerja SDM. SDM yang tidak memiliki kemampuan kecakapan atau keahlian akan tidak efektif dalam melaksanakan tugas dan pekerjaannya yang pada gilirannya kinerja perusahaan akan menurun;

2. Seleksi yang efektif adalah sangat penting karena dana diinvestasikan dalam menarik atau mengangkat SDM sebagai karyawan sangat besar. Kesalahan dalam mengadakan seleksi tercermin dari banyaknya permasalahan SDM yang muncul setelah mereka bekerja dan rendahnya produktivitas kerja; dan
3. Globalisasi yang disertai dengan revolusi komunikasi dan infromasi, kemajuan ilmu pengetahan dan teknologi, serta persaingan yang semakin ketat memerlukan SDM yang berkualitas tinggi, untuk itu seleksi memegang peranan penting.

$$
\text { Rivai dan Sagala (2013) }
$$

mengatakan bahwa proses seleksi adalah langkah-langkah yang harus dilalui oleh para pelamar sampai akhirnya memperoleh keputusan ia diterima atau ditolak sebagai karyawan baru. Proses tersebut pada umumnya meliputi evaluasi persyaratan, testing, wawancara, dan ujian fisik. Ada dua konsep penting yang harus diperhatikan untuk peralatan seleksi ini, yaitu reliabilitas dan validitas. Reliabilitas (dapat dipercaya) berhubungan dengan konsistensi pengukuran yang digunakan sepanjang waktu, dan juga pertimbangan ukuran berapa banyak kesalahan yang terlihat dalam pengukuran yang terjadi sekarang. Validitas adalah skor yang diberikan pada waktu tes atau wawancara sesuai dengan kinerja pekerjaan yang nyata. Beberapa instrumen yang dapat digunakan dalam seleksi, yaitu:

1. Surat-surat rekomendasi;

2. Borang lamaran;

3. Tes psikologi;

4. Wawancara;

5. Assessment center; dan

6. Drug test.

Dalam hal ini seperti yang dikatakan oleh Rivai dan Sagala di atas bahwa pengabdian ini merupakan salah satu bagian dari instrument seleksi, yaitu tes psikologi dan wawancara, sedangkan untuk LGD itu termasuk tes tambahan sebagai data pendukung untuk tes psikologi yang diberikan untuk melihat bagaimana kemampuan komunikasi, kepemimpinan, kerjasama, dan kemampuan peserta dalam 
membuat keputusan di dalam tim kerjanya.

Selanjutnya setelah proses tes psikologi, LGD, dan wawancara dilakukan, akhirnya seluruh data yang diperoleh kemudian dilakukan integrasi data dan sampai terakhir tersusunlah laporan hasil pemeriksaan psikologi. Dalam hal ini di dapatkan dari target peserta yang lulus seleksi, yaitu dari 203 peserta yang ikut serta dalam seleksi dan yang lulus hanya 136 peserta.

\section{SIMPULAN}

Berdasarkan hasil seleksi calon karyawan baru pada posisi ini disimpulkan bahwa Pada program pengabdian ini melakukan kegiatan seleksi karyawan pada posisi assistant superintendent, dengan proses seleksi karyawan yang dilakukan dimulai dari tahap tes psikologi, tahap Leaderless Grup Discussion (LGD), dan wawancara. Dalam program pengabdian ini dimana setiap peserta yang ikut dalam mengikuti dan menyelesaikan setiap tahapan seleksi yang diberikan.

Jumlah calon karyawan yang lulus, dan mengikuti seleksi pada tahapan psikotes, LGD, dan Wawancara adalah 203 orang peserta, dengan jumlah 136 orang yang berhasil lulus.

\section{DAFTAR PUSTAKA}

Ardana, I. K., Mujiati, N. W., \& Utama, I. W. M. (2012). Manajemen Sumber Daya Manusia. Yogyakarta: Graha Ilmu.

Mondy, W. (2008). Manajemen sumber daya manusia. Jakarta: Penerbit Erlangga.

Nurhuda, E., Hmidi, D., \& Riza, M. F. (2014). Analisis pelaksanaan program rekrutmen, seleksi, penempatan kerja, dan pelatihan karyawan (Studi pada karyawan Biro Perjalanan Umum Rosalia Indah). Jurnal Administrasi Bisnis (JAB), 9(1), 1-9.

Rafii, M., \& Andri, S. (2015). Pengaruh rekrutmen dan penempatan karyawan terhadap kinerja karyawan pada PT. Bank Riau Kepri Pekanbaru. Jom FISIP, 2(1), 1-12.

Rivai, V \& Sagala, E. J. (2013). Manajemen Sumber Daya Manusia untuk Perusahaan (cetakan kelima). Depok: PT Rajagrafindo Persada.

Sujanto, A. (2009). Rekrutmen dan seleksi berbasis kompetensi: tantangan dalam pemenuhan kebutuhan tenaga kerja pada knowledge society. Infokom, 1, 1-10.

Widiyantoro. (2012). Pengaruh seleksi, penempatan tenaga kerja dan pengembangan pegawai terhadap produktivitas kerja pegawai pada inspektorat Kabupaten Kediri. Jurnal Ilmu Manajemen: Revitalisasi, 1(3), 145-156. 